\title{
La obra literaria, la teoría de la recepción y el lector competente: un breve acercamiento(1)
}

\section{The literary work, the theory of reception and the competent reader: a brief approach}

\author{
Diana María Aguilar Guerrero \\ Magíster (T) en Traducción e Interpretación \\ Universidad de Buenos Aires-Argentina \\ Licenciada en Educación Básica con Énfasis en Humanidades: \\ Español y Lenguas Extranjeras \\ Universidad Pedagógica Nacional \\ diaguilar017@gmail.com \\ Artículo recibido el 22 de abril del 2016 \\ Aprobado el 02 de mayo del 2016(2)
}

\section{Resumen}

En el siguiente artículo se propone el camino que debe recorrer el lector de una obra literaria que sea perteneciente al canon. Se considera la elección del texto literario y pasando por la teoría de la recepción desmantelar el artificio, que es de lo que se encuentra hecha una buena obra, para finalmente llegar al goce estético, que no es otra cosa que el entendimiento y comprensión de lo que un prodigioso escritor quiso ocultar para exigir al lector a no quedarse con una lectura inocente y superficial. No está de más la crítica a la flexibilización académica del modelo pedagógico que poco se ocupa de una lectura apropiada y llena de significado.

Palabra Clave: Lector competente, obra literaria, hermenéutica, teoría de la recepción, goce estético. 
The following article aims to announce the path that should be taken by those who judge themselves as good readers of literature. First of all, it is considered the choice of the literary text and through the theory of reception dismantle the artifice contained in a good literary work, to finally get the aesthetic pleasure, that is the understanding and total comprehension of what a prodigious writer wanted to hide in order toengage the reader in a profound and careful reading.

Key word: Proficient reader, literary work, hermeneutics, reception theory, aesthetic enjoyment.

\section{Introducción:}

Hoy por hoy leer es casi un acto de rebeldía, pues muy pocos se interesan por una buena lectura.A leer se enseña durante los primeros años de vida que el individuo tendrá que cultivar a lo largo de su existencia; sin embargo, la experiencia nos ha enseñado que, por lo general, la lectura se queda en una acción poco trascendental en sociedades para las que aprender a leer es algo que se da por una mera necesidad de supervivencia y entendimiento pragmático del mundo circundante, más no pensada como una acción placenteraque suscita afición y disfrute ante las infinitas posibilidades de descubrir y acercarnos a nuevos universos. De ahí que no siempre los individuos hacen una lectura completa, pero no solamente con respecto a terminar el libro, sino a captar las ideas y razonamientos contenidos en el texto. En muchos casos es necesario tener cierto bagaje para llegar a una completa comprensión y para ello tambiénes necesario haber leído. Si un estudiante quiere adentrarseen los mundos fantásticos que Borges creó con su ingeniosa y cuidadosa escritura, deberá saber que sus cuentos están plagados de referencias al mito clásico griego, al universo, al infinito e incuso al azar.

Con esto en mente, se podría indagar si la satisfacción de una lectura compleja atañe a un mundo exclusivo y limitado en el que muy pocos sobreviven ¿Qué pasa cuando un individuo se enfrenta a la lectura de un texto literario? La respuesta es nada, nada cuando no se comprende lo que el autor quiere comunicar en su totalidad.

Teniendo en cuenta lo antes dicho, a continuación se propone el recorrido que debería seguir aquel que pretenda enfrentarse y comprender un texto literario, donde, a través de algunos postulados teóricos sobre la teoría de la recepción, pueda desmantelar el artificio y alcanzar el goce estético de la lectura. 


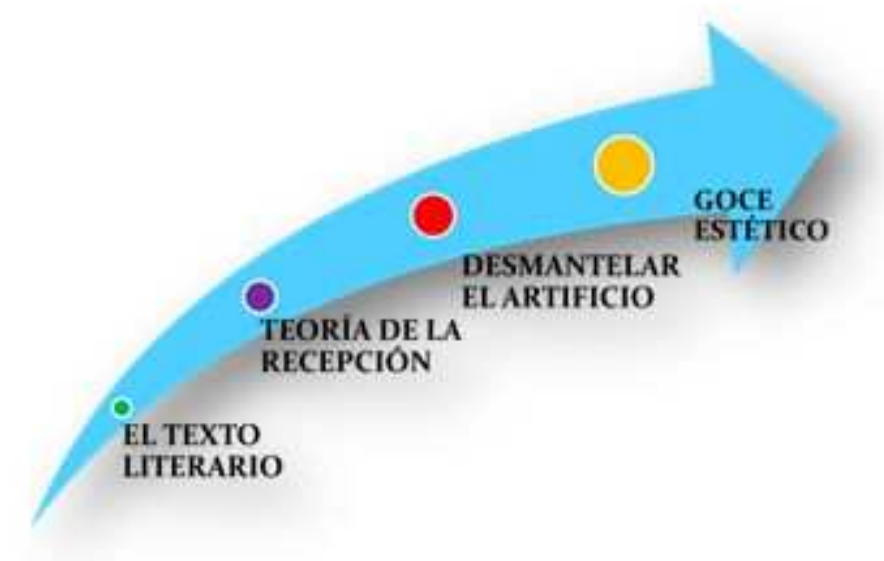

Imagen 1. Del texto Literario al Goce Estético. Aguilar, Diana (2016)

\section{Metodología}

Si se piensa una obra literaria como una obra de arte, a través de la teoría de la recepción, se examina y se estudia, no desde su producción, crítica o análisis a través del tiempo, sino desde el punto de vista del lector, es decir, la obra desde su percepción. Gracias a este hecho, la Estética de la Recepción, cuyos representantes son Hans Robert Jauss y Wolfgang Iser, sitúan al lector como parte activa y participativa de la obra de arte, es decir, la obra literaria no es per se sino más bien por la gracia, interpretación y respuesta del lector. De ahí que dicha teoría haya tomado dos líneas de pensamiento básicas, pero ambas teniendo en cuenta al lector como actor activo y parte clave del proceso de lectura: por un lado la Estética de la Recepción y por otro la Teoría de la Respuesta del Lector.

La Estética de la Recepciónproviene de la fenomenología e indaga al texto desde un horizonte de expectativas; de esta manera se analiza la historia de la obra, su transformación a través del tiempo, así como su interpretación bajo diferentes contextos sociales en épocas diferentes. En definitiva "examina cómo una generación transmite a otra los temas literarios, cómo ésta y las siguientes van cambiándolos y cuáles son las condiciones para que el lector los comprenda." (Valbuena, 1997:452).

En cuanto a la Teoría de Respuesta del Lector, de origen norteamericano, utiliza diferentes técnicas para acercarse al lector y hacerlo protagonista del proceso cuando se analiza la obra en la conciencia del individuo, dejando de ser objetiva para pasar al plano de la subjetividad. Con ello, se pretende considerar cómo y por qué motivos el lector produce su propio significado, llena los espacios en blanco, sospecha, presiente, supone, 
calcula, deduce y así, paulatinamente, se cumplen o no sus expectativas.

La teoría de la recepción entonces se preocupa por poner al individuo como parte activa y capaz de percibir los aspectos polisémicos de un texto literario. En este sentido, es claro que se hable de un lector que prefiera la literatura que haga parte del canon, y no solo un lector cuyas preferencias no van más allá de los libros populares o triviales para los que no es necesario hacer esfuerzos desmedidos en orden a lograrsu comprensión;en consecuencia,los textos que no exigen dela perspicacia del lector, ni de un acervo cultural amplio, que no esconden ni complejizan, producirán en el lector un efecto triunfalista sin mayor trascendencia; y nada extraño sería que el individuo haga alarde de su logro y comprelas publicaciones del autor que permitió una lectura simple ¿Es esa la clave de la cuantiosa venta de libros simples de autoayuda, superación, e inteligencia emocional? Dicho de otra manera, hay publicaciones que se encargan de producir sensaciones pocointensas, insignificantes y efímeras que no aportan mucho a nivel mental;son esos libros que rayan en la obviedady hacen sentir muy bien al lector, pero ese efecto está destinado a desvanecerse rápidamente.

Como bien apunta Faciolince (2010) "si fueran libros profundos, complejos literariamente, con ideas serias y bien elaboradas, el público no los compraría porque las masas tienden a ser incultas y a tener muy mal gusto". Se aclara, desde luego, que el desinterés por la literatura imbricada, enmarañada, provocadora y que genera pensamiento, no es algo de nuestra época, ya Aristóteles afirmaba en su poética que el discurso no era de libre difusión, y por ello dividió y clasificó los géneros en altos y bajos: el género alto era la tragedia, a la que solo tenían acceso aquellos quienes ocupaban las mejores posiciones sociales; por el contrario, la comedia era el género para las masas, ya que no era necesario poner al pueblo en tareas de difícil comprensión. Incluso Nietzsche (2005) cataloga al lector moderno como aquel que no tiene tiempo para disfrutar de pasajes profundos, y que por el contrario, bajo el mandato de un modelo mercantilista, logra que el individuo prefiera adquirir libros con contenidos sencillos y de rápida digestión, pues no tiene tiempo para ser el lector paciente que exige de buenas lecturas.

\section{Resultados}

Ciertamente la estructura lingüística de algunos libros es muy básica, yes precisamente por esto que son textos que no forman parte del canon, y a los que no valdría la pena incluir para un análisis desde la teoría de la recepción, porque a ese tipo de argumento, no le hace falta la astucia, discernimiento y talento del lector, pero que resultan atractivos para un público sin ninguna base literaria. Luego entonces nos asalta nuevamente el cuestionamiento de si el arte y la literatura hacen parte de un universo elitista al que muy pocos tienen el privilegio de pertenecer. Para usar las palabras del autor español Vila-Matas (2002: 64) 
(...) todo el mundo, exactamente todo el mundo, se siente capaz de escribir una novela sin haber aprendido nunca ni siquiera los instrumentos más rudimentarios del oficio, y sucede también que el vertiginoso aumento de estos escribientes ha terminado por perjudicar gravemente a los lectores, sumidos hoy en día en una notable confusión.

Ahora bien, una buena literatura se encarga de hacer que el lector participe haciendo abstracciones y que deba indagar para reconocer eso que el autor disfrutó escondiendo para que fuese hallado, es decir, desmantelar el artificio. Es entonces cuando la teoría de la recepción vendría a ser el desmantelamiento de los artificios, si es que el propósito es recepcionar y analizar a profundidad una obra. En este sentido Alexander Potebnia sostenía que

"No hay arte y, en particular, no hay poesía, sin imagen...La relación de la imagen con lo que ella explica puede ser definida de la siguiente manera: a) la imagen es un predicado constante para sujetos variables, un punto constante de referencia para percepciones cambiantes; b) la imagen es mucho más simple y mucho más clara que lo que ella explica" es decir. "puesto que la imagen tiene por finalidad ayudarnos a comprender su significación y dado que sin esta cualidad no tiene sentido, debe sernos más familiar que lo que ella explica"(Todorov, 1978: 55)

Shklovski disiente frente a tal postura y a partir de ello propone la idea de desaumatización que refiere al proceso que oponerse al carácter y a las reglas comunes del lenguaje, es decir, ir en contra de la convencionalidad y acercándose más ala disconformidad y al extrañamiento.

Para dar sensación de vida, para sentir los objetos, para percibir que la piedra es piedra, existe eso que se llama arte. La finalidad del arte es dar una sensación del objeto como visión y no como reconocimiento: los procedimientos del arte son el de la singularización de los objetos, y el que consiste en oscurecer la forma en aumentar la dificultad y la duración de la percepción. El acto de percepción es en arte un fin en sí y debe ser prolongado. El arte es un medio de experimentar el devenir del objeto: lo que ya está "realizado" no interesa para el arte. (Todorov, 1978: 60)

Para descifrar el artificio se debe contar con las herramientas necesarias para hacerlo;debe ser aquel que sea competente y pueda analizar el texto y por ende el encargado de darle el sentido. Heráclito afirmaba que nadie se baña dos veces en el mismo río, y si se piensa en una obra como una criatura que evoluciona con el paso del tiempo y cuya lectura es inacabable,nunca habrá una lectura igual a otra, pese a que sea el mismo texto, porque se hace desde diferentes circunstancias, perspectivas, contextos y experiencia: la obra evoluciona en tanto evoluciona el lector. Cada lector hace una construcción diferente de la obra, y lo logra teniendo en cuenta el mundo circundante. Tener en cuenta todo esto hará más fácil desenvolver eso, el regalo que el autor, a través del artificio envuelve y oculta para que sea un lector atento quien pueda desenvolverlo y encontrar el obsequio: es 
justo ahí, en ese momentoque el lector llega algoce estético de la literatura.

\section{Conclusiones}

Como se decía líneas arriba, el lector deberíacompartircierto vínculo y bagaje cultural con la obra,lo que permitiría más fácilmente el gusto estético; no quiere decir que sea requisito, pero que si su meta es la completa comprensión del texto, deberá recorrer un camino un poco más complejo, dado que generalmente las palabras que escoge decir un autor para transmitir sus pensamientos tienen un significado profundo, que va más allá, que no se queda en la mera literalidad, sino que juega con conceptos que se incluyen en un sinnúmero de temáticas y abstracciones. Quizás es esa la clave de la creación del artificio que muy pocos escritores logran con viveza y genialidad; por ende, es cuestión y tareadel buen lector, descubrir y develar el camino imbricado.

Por qué no hacer de nuevo una lectura, ya no tan inocente, de La Celestina (que se lee en la secundaria) y abordarla a la luz del erotismo de George Bataille, seguramente a los mismos personajes ahora se les proporciona rasgos más cercanos a la animalidad y analizar cómo, a través de sus acciones, buscan trasgredir interdictos. Aura, del mexicano Carlos Fuentes, es un texto que no está desprovisto de señales, huellas, marcas y de una simbología especial por lo que quizás Jüng,junto con una mirada existencialista nietzscheniana o sartriana y un diccionario de signos y símbolos, nos lleve a una historia más profunda y significativa. Lindo es entender que autores como Umberto Eco hacen maravillas y a través del texto juegan y seleccionan a su lector ideal. En El Nombre de la Rosa, durante las cien primeras hojas, Eco logra que el lector experimente el cansancio que sienten los personajes. Quien logre soportar el cansancio que se transmite en las primeras líneas tendrá una mayor posibilidad de disfrutar el texto y su pleno contenido. Indudablemente, la dilucidación de la trama en cualquier texto literario, así como el pleno conocimiento de los recovecos, complementan la lectura con lo cual se logra un quehacer menos ingenuo para volverse enriquecedor, y donde la percepción de la obra contribuirá a mejorar la sensibilidad que permite la apreciación de la estética particular de cada texto.

El goce, el valor estético no reside más que en el pleno entendimiento y comprensión de la obra que, así como cualquier expresión artística, está a disposición de todos, pero no se garantiza el mismo impacto y disfrute al mismo nivel de quien lo hace mediante una lectura concienzuda, inteligente, investigativa, curiosa y relacional. No se quiere decir que la literatura esté vedada si no se tiene un conocimiento previo, o si no se lee desde cierta teoría, por supuesto las lecturas inocentes son válidas pero estas se caracterizan por dejar una dicha inconstante, pequeña, vaga y ligera que desvanece pronto presa del olvido. 
La teoría de la recepción pone de manifiesto el importante papel que juega el lector, pero al mismo tiempo presume que el lector cuenta con las herramientas necesarias para llevar a cabo su cometidosin riesgo a fracasar. Desafortunadamente, los modelos educativos que hoy prevalecen han logrado que la educación sea un poco flexible y elemental, pues se piensa en la cobertura más que en la calidad, y esa falta de calidad desdeña directamente la lectura y los procesos subsecuentes como la escritura y el desarrollo de la creatividad. Con todo, esta teoría es funcional siempre y cuando el individuo cuente con las armas necesarias para convertirse en el lector ideal y que deberían seradquiridas durante la formación académica escolar, de ahí que sea de gran importancia la labor del docente que debe crear todas las oportunidades y poner a disposición de los estudiantes instrumentos para enseñar el camino de la lectura consciente y significativa.

Es preciso leer para escapar de la absurda cotidianidad, para adentrarse en la realidad de la ficción, la verdad de la mentira, pues la labor del buen escritor es situar la realidad en un nivel supremo y diferente donde pondrá a prueba no solo su capacidad de fabular, convencer y persuadir, sino la habilidad del lector para entender y llenarse del artificio ofrecido; así pues, lo ideal sería leer por placer, y a través de la exégesis misma, llegar al goce estético de la obra. Felizmente se cuenta con un rango amplio de excelente literatura y teoría que permite vehicular lo bello y el gusto estético, que sin lugar a dudas contribuirá al entendimiento de los individuos, pero sobre todo a humanizarnos mientras estamos de paso por la vida.

\section{Referencias}

Castañeda, M. (1998) Aura: ¿reinvención del pasado? [En línea] http://www.letralia.com/271/ensayo01.htm [Recuperado 25-07-2015]

Faciolince, H. (2010) “¿Por qué hay que leer literatura?”. En: La Gaceta Literaria. [En línea] http://www.lagaceta.com.ar/nota/366654/la-gaceta-literaria/lagaceta.com.ar [Recuperado 20-07-2015]

Fuentes, C. (1962) Aura. México: Ediciones Era S.A. de C.V. Mendoza, M. (1989) “Aura de Carlos Fuentes.Un aquelarre en la calle donceles 815”. En: Anales de la Literatura Hispanoamericana Núm. 18. Madrid: Universidad Complutense. [En línea] http://revistas.ucm.es/index.php/ALHI/article/viewFile /ALHI8989110191A/23846 [Recuperado 20-07- 2015]

Morón, L. (2006). Módulo Teoría Literaria: Estética De La Recepción Literaria. Perú: Universidad Nacional de Educación Enrique Guzmán y Valle. Nietzsche, F. (2005). Así Habló Zaratustra. Madrid: Editorial Edaf.

Pérez, P. (2008). El gusto estético. La educación del (buen) gusto. España: Universidad de Navarra. [En línea] http://www.unav.edu/web/estudios-sobre-educacion/articulo?idArticulo=1104945 [Recuperado 


\section{5- $\quad 07-2015]$}

Soto, A. (2003). Ricoeur y la teoría de la recepción. México: UNAM Anuario 2002.

Todorov, T. (1978). Teoría de la Literatura de los Formalistas Rusos. (Páginas 55-70). México: Siglo XXI.

Valvuena, F. (1997). El Análisis de la Recepción. Madrid: Noesis Vila-Matas, E. (2002). El Mal de Montano.

Barcelona: Editorial Anagrama

\section{Notas}

(1). Citar este artículo como: Aguilar, D. (2016) "La obra literaria, la teoría de la recepción y el lector competente: un breve acercamiento". En: Revista La Tercera Orilla (16). Bucaramanga: Universidad Autónoma de Bucaramanga

(2). Artículo arbitrado por Erika Moreno Bueno. Doctora en Semiótica (Tesista). Universidad Nacional de Córdoba - Argentina. 